\title{
Blomstrand Type Chondrodysplasia
}

National Cancer Institute

\section{Source}

National Cancer Institute. Blomstrand Type Chondrodysplasia. NCI Thesaurus. Code C131420.

An autosomal recessive lethal condition caused by inactivating mutation(s) in the PTH1R gene, encoding parathyroid hormone/parathyroid hormone-related peptide receptor.

This condition is characterized by short limbs, polyhydramnios, hydrops fetalis, facial anomalies, increased bone density, and advanced skeletal maturation. 